\title{
ニューラルネットワークを利用した鋼板の腐食位置標定*
}

\author{
稲葉 藍子*1, 本間 恭二*2, 村上 小百合*2 \\ 小池卓二*2, 山田 實*3
}

\section{Corrosion Source Location in Plate of Steel Using Neural Network}

\author{
Aiko INABA, Kyoji HOMMA*4, Sayuri MURAKAMI, \\ Takuji KOIKE and Minoru YAMADA
}

\footnotetext{
${ }^{* 4}$ Department of Mechanical Engineering and Intelligent Systems, The University of Electro-Communications, 1-5-1 Chofugaoka, Chofu-shi, Tokyo, 182-8585 Japan
}

\begin{abstract}
A new technique to locate a defect, combining acoustic emission and neural network, is proposed to assess the condition of the storage tank floor. Artificial acoustic emission source by means of a pencil lead break and acoustic emission source cause of corrosion in steel plate is located using neural network trained by time lag of artificial acoustic emission, $\mathrm{P}$-wave, $\mathrm{S}$-wave and Rayleigh wave. It turned out that artificial acoustic emission arrived at sensor is $\mathrm{P}$-wave and acoustic emission course of corrosion is S-wave or Rayleigh wave. Same experiment is made on a specimen of bottom plate of real tank. As a result, corrosion source location using neural network is possible steel plate extended corrosion.
\end{abstract}

Key Words : Acoustic Emission, Neural Network, Nondestructive Inspection, Corrosion, Location

\section{1. 粕言}

屋外石油タンクの腐食損傷による危険物の漏洩を防 ぐため, タンク底板の腐食の進行をモニタする技術開 発が求められている ${ }^{D}$ 。 その一つとしてアコースティ ック・エミッション (AE) 法が注目されており ${ }^{2}, \mathrm{AE}$ 発生数から腐食の活性度を測定できることなどが知ら れている ${ }^{3)}$.また, ニエーラルネットワーク $(\mathrm{NN})$ を利 用したパイプの欠陥位置検出技術の開発も試みられて

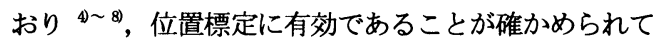
いる.

そこで，本研究では，危険物貯蔵施設の健全性確保 を目指して，鋼板が腐食することで発生する AEを計 測し，NN を利用した腐食源位置標定の可能性を調べた. 始めに，ピットを設けた銅板を用いて，擬似 $\mathrm{AE}$ 波と 腐食のときに発生する $\mathrm{AE}$ 波の種類の違いを調べた. 次に, N の学習点数が位置標定精度に与える影響について調べ

* 原稿受付 2004 年 4 月 20 日.

*1 電気通信大学大学院電気通信学研究科(- 182-8585 調布市 調布ヶ丘 1-5-1).

*2 正員, 電気通信大学知能機械工学科.

*3 正員, 独立行政法人消防研究所 (画181-8633 三䳸市中原 3 14-1).

E-mail : homma@bio.mce.uec.ac.jp
た.

\section{2. 錀板の腐食 AE 源位置標定}

位置標定は AE 波が最初にセンサへ到達する時刻を 求めることが必要となる. このとき $\mathrm{AE}$ 源で発生した 波の種類や大きさによって, センサで受信する波形は 異なるため, 最初に到達する波がどのようなものであ るかを調べた。

$2 \cdot 1$ 試呀片と実㗨装置 石油タンク底板に使わ れているSS400 の板材 $(200 \mathrm{~mm} \times 250 \mathrm{~mm} \times 6 \mathrm{~mm})$ に, 腐食 ピットを想定したものを 2 籄所（Pit 1 : 直径 $10 \mathrm{~nm}$, 深さ $3 \mathrm{~mm}$ ，Pit 2 : 直径 $3 \mathrm{~mm}$ ，深さ $1.5 \mathrm{~mm}$ ）作製した. 試 験片を図 1 に示す. 4 つの AEセンサ（R15，PAC製）に 真空グリスを塗布し，マグネットジグを用いて試験片 の四隅に固定した. プリアンプ(1220A，PAC製)により $\mathrm{AE}$ 波形を 40dB 増幅し, $\mathrm{AE}$ 測定器 (Disp-TRA, PAC 製)に取り込んだ

2・2 Nを用いた位置標定 Nの計算はニューラルネ ットワークシミュレータ (SNS) を用い, 学習アルゴリ ズムはバックプロパゲーション法とした. 


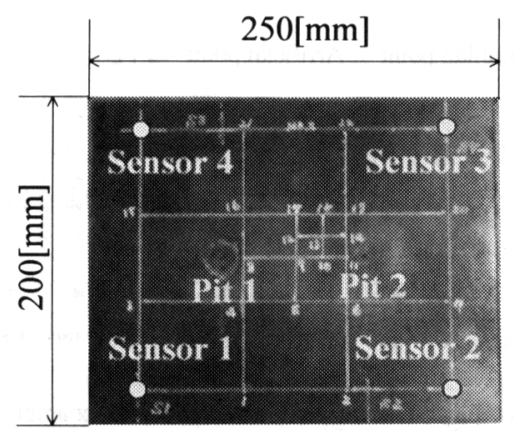

Fig. 1 Specimen with etch pit

$\mathrm{NN}$ の人力は $\mathrm{AE}$ 波の各センサへの到達時間差, 出 力は $\mathrm{AE}$ 発生位置とし, 式（1）により各データの正規 化を行った.

$$
x=x_{0} / x_{\max } \times 0.6+0.2
$$

$x_{0}$ : 個々の到達時間差 (入力) と座標 (出力)

入力值の $\mathrm{x}_{\mathrm{nex}}$ には $\mathrm{x}$ が 0.8 を超えないような任意の值を 設定し, 出力值の $x_{\text {nax }}$ はセンサ間の最大距離を用いて, デ 一タが $0.2 〜 0.8$ の範囲に入るよう正規化を行なうことで 最適化した

$2 \cdot 3$ 波動の種類シャープペンシルの芯を圧折す ることにより発生する擬似 $\mathrm{AE}$ 波と，腐食により発生する $\mathrm{AE}$ 波とでは波動の種類やエネルギーが大きく異なる. そ こで，それぞれの $\mathrm{AE}$ 波が，ある一定距離を伝播してセン サに到達したとき，縦波，横波，レイリー波のいずれの 波動であったかを調べた。

\section{2・3・1 擬似 AE O位置標定ピット内でシャー} プペンシルの芯を圧折することで擬似 $\mathrm{AE}$ を発生させ, その位置標定を行なった. NNの学習には以下の 3 通り の学習データを用い, 波動の種類を推定した. また, NN の学習回数は 1 万回とした.

(1) 擬似 $\mathrm{AE}$ 到達時間差

（2）繸波理論音速から計算した到達時間差

（3）横波理論音速から計算した到達時間差

学習点は 47 箇所とした. 図 2 (1)〜 (3)にそれぞれ の場合の位置標定結果を示す.

擬似 $\mathrm{AE}$ 到達時間差およひ䋛波理論音速（5950[m/s]）を 用いて学習を行なった場合はピット位置に標定されたが, 横波理論音速 $(3240[\mathrm{~m} / \mathrm{s}])$ を用いた場合はピットの遠方 に標定された.このことから, 擬似 $\mathrm{AE}$ 発生によりセンサ に到達した波は縦波であると推定される.

2.3.2 腐食 $\mathrm{AE}$ の位置標定 ピット内に鉄粉, 木炭等の触媒を添加した $3 \% \mathrm{NaCl}$ 水溶液を加えて腐食を 促進させた場合と， $3 \% \mathrm{NaCl}$ 水溶液のみを加えて腐食を 促進させた場合に発生した $\mathrm{AE}$ を計測して位置標定を
行ない, 結果を比較した. NNの学習には次の 4 通りの 学習データを用いた.

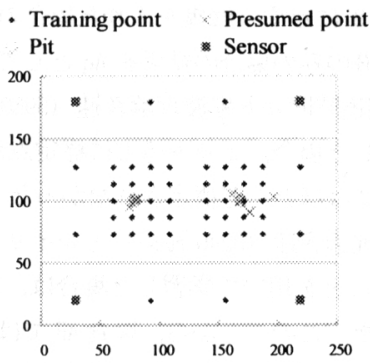

(1) Artificial AE

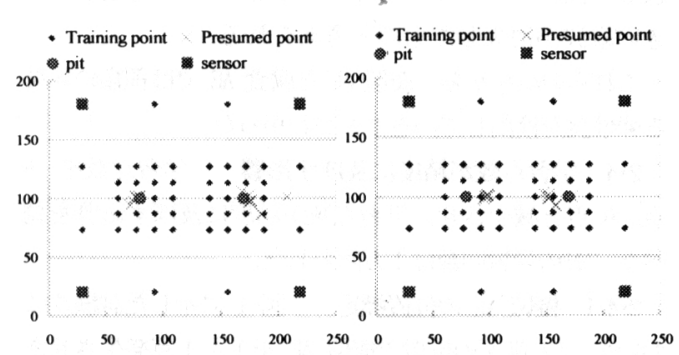

(2) P-wave

(3) S-wave

Fig. 2 Presumed source location of artificial $\mathrm{AE}$

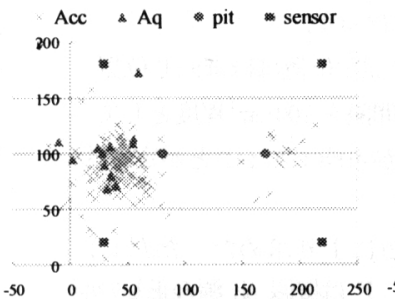

(1) Artificial AE

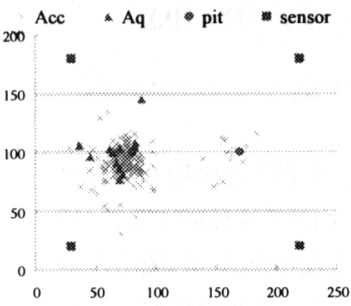

(3) S-wave

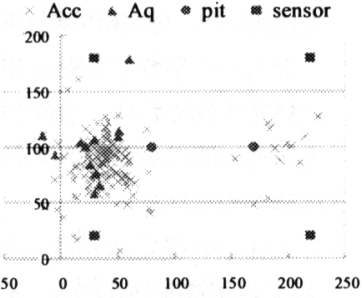

(2) P-wave

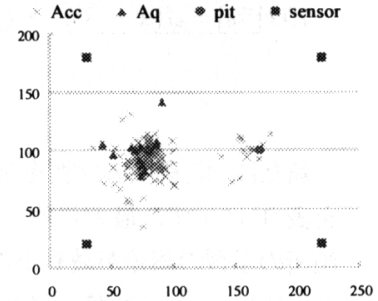

(4) Rayleigh wave
Fig. 3 Presumed source location 
（1）擬似 $\mathrm{AE}$ 到達時間差

（2）縦波理論音速から計算した到達時間差

（3）横波理論音速から計算した到達時間差

（4）レイリー波音速から計算した到達時間差

結果を図 3 に示す. 触媒を入れた場合の結果を Acc, $3 \% \mathrm{NaCl}$ 水溶液のみの場合の結果を $\mathrm{Aq}$ として表した.

擬似 $\mathrm{AE}$ 到達時間差と縦波理論音速（5950[m/s]）を 用いて学習した場合, ピット遠方に標定点が集中し, ピット位置にはほとんど標定されなかった. しかしな がら, 横波理論音速 $(3240[\mathrm{~m} / \mathrm{s}])$ とレイリー波音速 $(2980[\mathrm{~m} / \mathrm{s}])$ とを用いて学習した場合は, ピット近傍 に標定された.このことから, 腐食 $\mathrm{AE}$ では横波もし くはレイリー波（データからは判別できない）がセン サに到達したことがわかった. 腐食 $\mathrm{AE}$ は擬似 $\mathrm{AE}$ と比 較して波のエネルギーが非常に小さいため, 減衰の大 きい縦波が消失したものと考えられる.

これらの結果から，擬似 $\mathrm{AE}$ と腐食 $\mathrm{AE}$ では種類の異な る弾性波を検出していることがわかった.

2.4 学習点数が精度に及ほす影瑹 学習点数を 15 点, 9 点と減少させ, 学習点数が精度に及ぼす影響を調 ベた. Nの学習回数は 1 万回とした.

2・4・1 拶以 AE の位置标定 図 1 に示した試験片に おいて, 22 筒所の位置で擬似 $\mathrm{AE}$ を 1 点 1 点発生させた 発生位置を図 4 の×印で示す.これらのうち，15 箇所又 は 9 籄所で発生させた擬似 $\mathrm{AE}$ の到達時間差を $\mathrm{N}$ への入 力值としてNの学習を行なった. その後, 学習点を含む 22 箇所の擬似 $\mathrm{AE}$ について位置標定を行ない，その精度 を比較した．標定結果を図 5 に示寸.

どちらの学習でも擬似 $\mathrm{AE}$ 発生位置はほぼ同じ位置 に標定されており, 学習点間隔を $100[\mathrm{~mm}]$ 程度として も，その間にある点の標定が可能であることが定性的 に確かめられた.

これらの標定誤差は式(2)により求めた.ただし, $x, y$ は学習後の出力值, $X, Y$ は擬似 $\mathrm{AE}$ 源の正しい座 標， $D$ はセンサ間の最大跑離を表す.

$$
\operatorname{Err}[\%]=\sqrt{(x-X)^{2}+(y-Y)^{2}} / D \times 100
$$

新たに 47 箇所の学習を加えて誤差を比較したもの を表 1 に示す. 最大誤差, 平均誤差を比較すると 15 箇所の学習の䛊差が最も小さくなった. 47 箇所の学 習と比較して，学習筒所を减少させた場合においても， 定量的にも著しい違いはなかった.これらの結果より， 学習点と離れた位置に関しても著しく標定精度が落ち ることはないことがわかった。

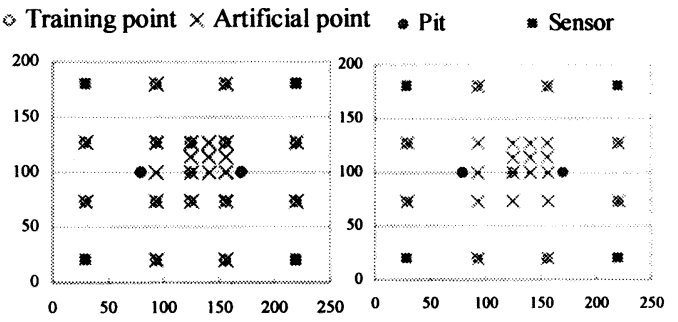

Fig. 4 Training point, actual point, sensor arrangement and pit location

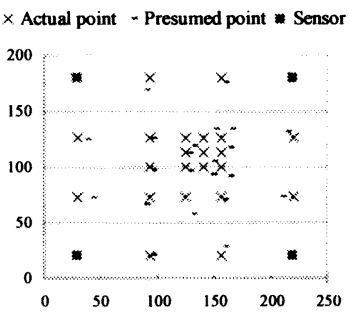

Training point : 47

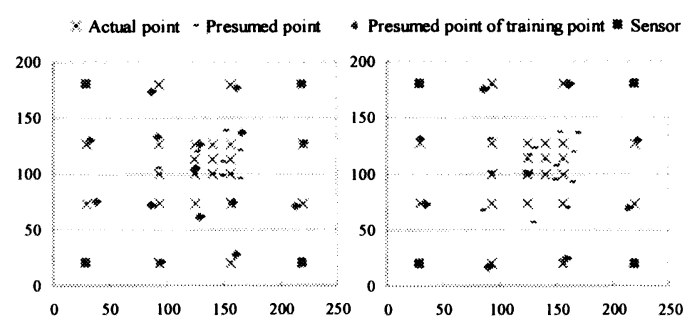

Training point : 15

Training point : 9

Fig. 5 Presumed source location ( $X$ :Actual point, $\diamond$ :Presumed point of Training point, -:Presumed point)

Table 1 Comparison with a major of error

\begin{tabular}{|c|r|r|r|r|r|r|}
\hline & \multicolumn{2}{|c|}{ Training point:47 } & \multicolumn{2}{c|}{ Training point: 15 } & \multicolumn{2}{c|}{ Training point:9 } \\
\cline { 2 - 7 } & distance[mm & error[\% & distance[mm & error[\% & distance[mm & error[\%] \\
\hline max. & 17.35 & 5.42 & 15.03 & 4.69 & 17.40 & 5.44 \\
\hline ave. & 8.44 & 2.63 & 7.38 & 2.31 & 7.71 & 2.41 \\
\hline min. & 1.99 & 0.62 & 1.18 & 0.37 & 0.44 & 0.14 \\
\hline
\end{tabular}

2・4・2 腐食AE の位置標定 図 1 に示した試験 片のピット内に, 触媒を添加した $3 \% \mathrm{NaCl}$ 水溶液を加 
えて腐食を促進させ, 発生した腐食 AE を計測して位 置標定を行なった.

$2 \cdot 3$ 節より得られた擬似 $\mathrm{AE}$ と腐食 $\mathrm{AE}$ での受信波の種類 の違いを考虑して, 学習データにはレイリー波速度から 求めた到達時間差を用いた. 学習点を 15 箇所とした場合 と 9 箇所とした場合について位置標定を行なった. 学習 回数は 1 万回とした. 標定結果を図 6 に示す. また, 式 （2）により求めた誤差の比較を表 2 に示す.

15 箇所, 9 箇所と学習点を減少させたが, どちらの場 合もピット位置に多く標定点が見られた. また, 表 2 よ り, 定量的にも著しい違いは見られなかった. これらの 結果より, 腐食位置近傍に多くの学習点を配置しなくて も腐食位置標定が可能であることがわかった.

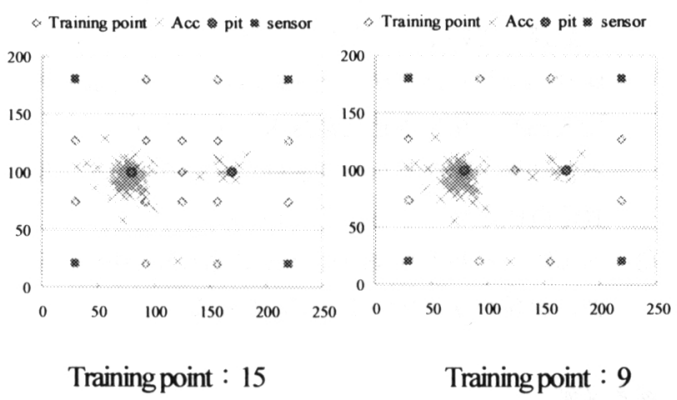

Fig. 6 Presumed source location of corrosion

Table 2 Comparison with a major of error

\begin{tabular}{|c|r|r|r|r|}
\hline & \multicolumn{2}{|c|}{ Training point : 15 } & \multicolumn{2}{c|}{ Training point : 9 } \\
\cline { 2 - 5 } & distance[mm] & error[\%] & distance[mm] & error[\%] \\
\hline max. & $\mathbf{8 7 . 8 8}$ & 35.15 & $\mathbf{8 9 . 8 5}$ & 35.94 \\
\hline ave. & 14.72 & 5.89 & 15.81 & 6.32 \\
\hline min. & 0.37 & 0.15 & 0.36 & 0.14 \\
\hline
\end{tabular}

$2 \cdot 5$ 実タンク底板の腐食位置標定 腐食の進行した 実タンクの底板を切出した試験片において, 鉄粉, 木炭 等の触媒を添加した $3 \% \mathrm{abl}$ 水溶液を加えてさらに腐食を 促進させた（図 7)．そのとき発生した AE を計測して位 置標定を行ない, 有効性を検討した.

(a)の試験片は, 比較的腐食が進行しておらず, 表面に赤 錆が多く見られた.（a)について，Nの学習に次の 3 通り の学習データを用いて位置標定を行なった.

(a-1) 擬似 $\mathrm{AE}$ 到達時間差

（a-2）横波理論音速から計算した到達時間差

（a-3）レイリー波音速から計算した到達時間差

一方，(b)の試験片はかなり腐食が進行しており，錆

こぶや貫通穴の箇所も見られた。この試験片は腐食面
の凹凸が激しいため，腐食面へのセンサの設置が困難 なことから, センサを腐食面の裏面に設置し, NNの学 習に次の 3 通りの学習データを用いて位置標定を行な った.

（b-1）縦波理論音速から計算した到達時間差

（b-2）横波理論音速から計算した到達時間差

（b-3）レイリー波音速から計算した到達時間差

それぞれの位置標定結果を図 8 (1)〜 (3), 図 9 (1)〜 (3)に示す.

この結果, 試験片（a)については横波，レイリー波 の理論音速から計算した学習データを用いた場合は腐 食位置とその近傍に多く標定点が見られたが，擬似 $\mathrm{AE}$ 到達時間差を学習データとして用いた場合は腐食位置 より離れた点に標定された. 試験片（b)については, 試験片（a)の場合と同様に, 縦波理論音速から計算し た学習データを用いた場合は腐食位置から離れた点に 標定されたが，横波の理論音速から計算した学習デー 夕の場合は, 腐食位置とその近傍に多く標定点が見ら れた. しかしながら、レイリー波音速を用いた場合は， 腐食位置近傍に標定されたものの腐食位置に標定され た点はなかった. この原因として, 表面波であるレイ リー波は媒質の表面に沿って伝わることから, 腐食面 の裏面に設置したセンサに直接に到達したのではなく， 端面から反射した波が到達したことが考えられる.

これらのことから, 試験片の腐食状態に関わらず, 腐 食 $\mathrm{AE}$ としてセンサに到達する波は横波もしくはレイリー 波であることがわかった．また，腐食が進行している場 合においても $\mathrm{N}$ を利用して腐食位置標定が可能であるこ とがわかった. 理論音速を用いて N の学習が可能である ことから, 屋外石油タンクなどの擬似 $\mathrm{AE}$ を発生させるこ とが困難な場合にも利用できると考えられる.

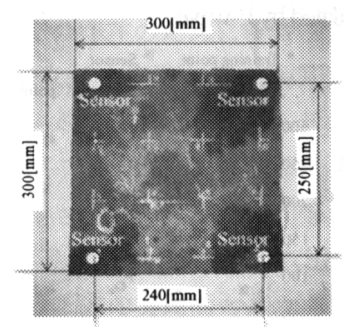

(a) Initial corrosion

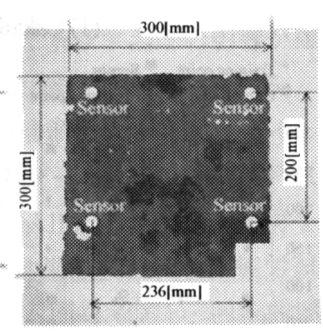

(b) Extended corrosion
Fig. 7 Specimen (Bottom plate of real tank) 


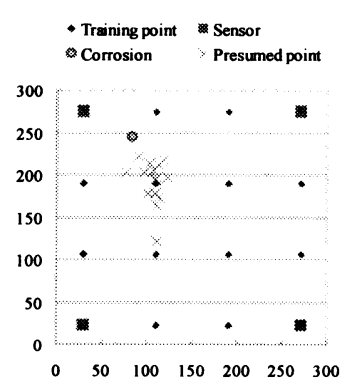

(1) Training of artificial $\mathrm{AE}$
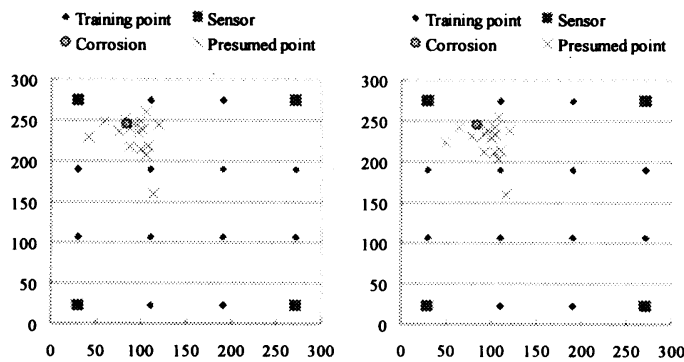

(2)Calculated by S-wave (3)Calculated by Rayleigh wave

Fig. 8 Presumed source location of corrosion (specimen (a))

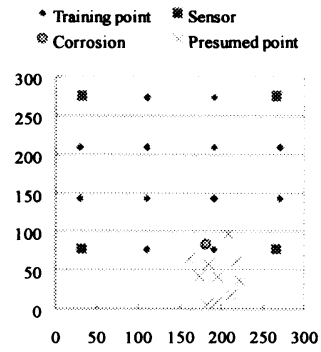

\section{(1) Calculated by P-wave}
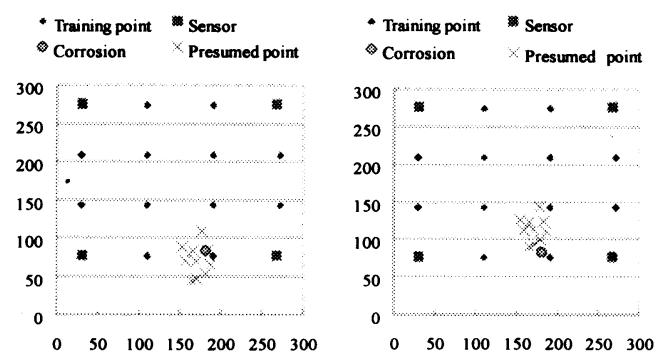

(2) Calculated by S-wave

(3) Calculated by Ravleigh wave

Fig. 9 Presumed source bcation of corrosion (specimen (b))
3. 結 言

屋外石油タンクの底板に用いられている鋼板を対象 として，その腐食ないし擬似 $\mathrm{AE}$ で発生する $\mathrm{AE}$ 波を 4 つの AEセンサで計測し, 波の到達時間差と位置の情 報を $\mathrm{NN}$ で学習することにより， $\mathrm{AE}$ 波の種類ならびに $\mathrm{AE}$ 発生位置を標定した. その結果, 以下の結論が得ら れた.

（1）鋼板上に設定した学習点からセンサまでのA E 波 の理論到達時間差を用いて NN の学習を行ない, $\mathrm{AE}$ 源の位置標定を行なったところ, シャープペン シルの芯の圧折による擬似 $\mathrm{AE}$ の場合は, 縦波が センサに到達していることがわかった. また, 人 為的に発生させた腐食 AEを標定した結果, 腐食 $\mathrm{AE}$ の場合はレイリー波（もしくは横波）がセンサ に到達していることがわかった.

（2）腐食の進行した実タンク底板から切出した試験片 で人為的に発生させた腐食 $\mathrm{AE}$ の位置標定を行な った結果, 腐食がかなり進行している場合でも腐 食位置標定ができることがわかった.

（3）本実験の範囲では NN の学習点の数は位置標定精 度に影響を与えないことがわかった。

\section{参考文献}

1)湯山茂德ほか, タンク底板の腐食損傷診断における国内外 の $\mathrm{AE}$ 試験適用の現状，圧力技術，40-4（2002），pp. 176-184 2) 山田宾ほか， $\mathrm{AE}$ 法による石油タンク底部の腐食損伤評価, 圧力技術, 40-4 (2002), pp. 222-227

3) Ferrer F. et al. , Acoustic Emission study of activepassive transitions during carbon steel erosion-corrosion in concentrated sulfuric acid, Corrosion Science, 44 -7 (2002), pp. 1529-1540

4) 消防研究所, ニューラルネットワークを用いた $\mathrm{AE}$ 源位置標 定, 消防研究所報告第 89 号 (200.3)

5) 消防研究所, ニューラルネットワークによる模型タンク底 板の AE 源位置標定，消防研究所報告第 91 号 (2001.3)

6) 真家敦子ほか, ニューラルネットワークによる $\mathrm{AE}$ 源の位置 標定およびその誤差評価に関する研究，日本機械学会論文 集, 65-634, A (1999), pp. 1187-1192

7)岡村由香ほか, ニューラルネットワークを利用したエルボ 型管継手の擬似 $\mathrm{AE}$ 源位置標定，非破壊検查，51-11（2002）, pp. 726-732

8) Salvatore B. et al, Leak Detection in Liquefied Gas Pipelines by Artificial Neural Network, AIChE Jornal, 4412 (1998), pp. 2675-2688 